\title{
WHAT CONTRIBUTION CAN INSIGHTS FROM THE COMPLEXITY SCIENCES MAKE TO THE THEORY AND PRACTICE OF DEVELOPMENT MANAGEMENT?
}

\author{
CHRIS MOWLES*, RALPH STACEY and DOUGLAS GRIFFIN \\ University of Hertfordshire, Hatfield, UK
}

\begin{abstract}
This paper offers a critique of existing ways of understanding management practice in International Non-Government Organisations (INGOs) and compares and contrasts these with insights drawn from the complexity sciences. The authors put forward a more radical interpretation of complexity theory as it might be taken up in organisations rather than suggesting that it can be accommodated with existing theories based in systems thinking. They suggest that understanding the process of organising as contingent, paradoxical and experiential could profoundly refocus the attention of managers and practitioners alike and lead to an intensifying of practice as more consciously political. In being more open to others, including their partners and beneficiaries, staff in INGOs may be more ready to change themselves and their ideas. At the same time, the authors point out the existing dynamics of current practice and the way it perpetuates itself, no matter how problematic. Copyright (C) 2008 John Wiley \& Sons, Ltd.
\end{abstract}

Keywords: complexity; management practice; systems thinking; paradox; social

\section{INTRODUCTION}

This paper will examine the contribution that insights from complexity theory can make to development studies, particularly the management of development and how it is practised. As we will explore below, complexity theory and theories of emergence are increasingly alluded to in the development literature. This paper intends to acknowledge these contributions but will also go on to differentiate an understanding of the more profound implications for thinking about development management and ethics that embracing the

*Correspondence to: Chris Mowles, Complexity and Management Centre, University of Hertfordshire, Hatfield, AL10 9AB, UK. E-mail: chris@redkitepartners.co.uk 
more radical insights from the complexity sciences might bring. It is our belief that the way that complexity theory generally gets taken up is as another 'tool' to add to existing approaches and methods. Rather than offering a profound challenge to the very nature of development management, as we hope to do here, insights from the complexity sciences are instrumentalised and presented as another means of improving taken for granted ways of managing.

Based on 25 years experience of working in the development sector and in organisations generally, we make the case that methods of managing international development have become so taken for granted as to be virtually unchallengeable. This has not always been the case in a sector which was initially suspicious of management theory and techniques, which Lewis (2001) explores to great effect. However, we argue that today managerialist methods have been adopted largely uncritically from the private sector and are now ubiquitous across all sectors of the economy, not just in International Non-Government Organisations (INGOs); there is a commonality of managerialist language and concepts that propels organisations in very different sectors to become isomorphic (Mowles, 2007), so that the potential for change through the emergence of difference is dampened down.

Our recent consultancies in the development sector in particular would lead us to believe that even gentle questioning of the theoretical underpinnings of development management can trigger energetic defensiveness on the part of those engaged in it. Further on in this paper we will offer some reasons as to why we think that managers and practitioners in the sector get caught up in such a vigorous defence of what they are doing. In the meantime we are adding our voices to the growing number of scholars critical of what Dar and Cooke (2008) call 'new development management', but who are still in the minority. These include Wallace et al. (1997), Quarles van Ufford and Giri (2003), Eyben (2005, 2006), Mosse (2005), Mosse and Lewis (2005) and Wallace et al. (2006). There are also scholars, such as Cooke (2004) and Murphy (2005), who have drawn attention to the way in which the INGO sector gets co-opted into a globalised liberal economic agenda.

\section{SOME COMMON UNDERSTANDINGS ABOUT DEVELOPMENT MANAGEMENT}

The following are what we understand to be some generalised assumptions about development management and practice derived from our work with staff and managers in the INGO sector, and from our reading of the development literature. As with any generalisation, what we write will tend towards the schematic and the description below masks a variety of different practices which could challenge the characterisation we are making. However, we hope the description we give is sufficiently recognisable of the dominant paradigm of understanding the task of the management of development to be a useful starting point to discuss the issues raised.

INGOs are engaged in a project of social transformation with and on behalf of the poorer two-thirds of the world's population. In order to address the scale of the task, managers often understand their role to be to envision an idealised and ambitious future with their staff which promises a substantive qualitative discontinuity with the present: a current example of this would be Save the Children's campaign to 'rewrite the future for children'. In other words, many INGOs create highly utopian vision statements which imagine 'a world where...' the opposite is the case of our current daily experience. Other examples would be 'all disabled people are able to enjoy their rights, fulfil their responsibilities and 
obligations and participate as fully as they choose at every level of society' (Action on Disability and Development ${ }^{1}$ ), 'a world without poverty and injustice in which every person enjoys their right to a life with dignity' (ActionAid), 'WaterAid's vision is of a world where everyone has access to safe water and sanitation'. Because managers in this sector understand that personal commitment and motivation are an important factor for staff, they will appeal to the INGO's moral mission and will stress the ambition and scale of the change which is being proposed as a means of generating excitement amongst staff. At the same time they will claim a significant contribution on the part of the INGO they manage to the social change to which they aspire.

Managers then assume that this idealism can then be directly realised with rational and linear planning techniques which scope the undertaking in terms of 'milestones' and 'deliverables' having imagined an idealised end point. As we heard one manager say in a strategy workshop, 'just think of the change that you want to bring about, and work backwards from there'. The logical framework planning tool is still very popular in the sector and is particularly favoured by the big donor agencies. It works exactly in the way that the manager we quote imagined it should: social interventions are understood to culminate in an end point of transformation, which can be planned for backwards in logical, rational and causal steps.

This amalgam of extreme idealism and rational planning is then taken up by managers in INGOs in their daily management of staff. Managers in most INGOs operate some form of 'performance management' by which they mean that staff are 'held accountable' for the very ambitious targets that the strategy process has produced and the commitments that the INGO may have made to donors. We have also come across instances in the consultancies we have undertaken with INGOs where managers take what seems to them the next logical step in trying to directly implement their idealisations by embarking upon 'culture change agendas' within the organisation. What they mean by this is that the perceived 'gap' between staff performance to date and what they need to do in order to achieve the new and ambitious vision is understood to arise from deficiencies in staff behaviour and attitude. This can lead to elaborate processes of rule-making and mutual policing to run meetings more efficiently, say, or to consider certain ways of talking and behaving as "nonnegotiable'. One INGO we came across encouraged staff to show each other red and yellow cards like football referees if they breached the new rules.

Staff in their turn take up these targets with the partner NGOs in the countries where they are working, and the working relationship then turns on the ability of the partnership to produce the kinds of results that may have been conceived in a different context at a different time separate from the local contingencies that INGO staff and local partners will encounter. In order to enhance the ability of local partner NGOs to 'deliver' the targets and milestones, staff in INGOs will undertake training with local partners, or 'capacity building', as it is commonly termed, which in effect often constitutes training in the methods and techniques that staff in INGOs themselves use to run their own organisations. This contributes to the isomorphic dynamic which we alluded to above where local NGOs are funded and encouraged to become more like the organisations which fund them.

Managers and staff in INGOs make substantial claims for the quality of their working relationships with local partner NGOs, which they will say is based on partnership, participation and consultation. Most are aware, however, of the problematic nature of a relationship where one side has the money and the other needs it. Staff in the field are often

\footnotetext{
${ }^{1}$ http://www.add.org.uk/
} 
in an unenviable position of being on the one hand forced to deal with local contingencies, and on the other hand being 'held accountable' for targets which they may have had no hand in setting. It has become clear to us that this can cause profound ethical and conceptual confusion for staff on the ground who have raised questions with us such as: 'what happens if our partners start saying things that we disagree with?' or 'how can we accommodate our long-term partners if they do not fit within our new strategy?' Part of the difficulty for managers and staff in INGOs is the reconciling of the competing claims and loyalties: their commitment to their promises of transformation, their contractual obligations to donors based on predictions of outcomes sometimes as much as 5 years into the future, their reward systems which are often predicated on fulfilling these promises and then their historical solidarity with their local partners, who are the ones dealing with the day-to-day vagaries of implementing the development projects.

\subsection{Theoretical Underpinnings of the Dominant Paradigm}

We are arguing that managers in many INGOs have adopted management theories and taken for granted ways which are based on a rationalist understanding of the world expressed in systems theory. The assumption is that methods that have proved so successful in analysing the natural world will be equally successful in the social world. Systems theories were first imported into organisational theory from engineering and the biological sciences in the 1950s. Principal among them was first order systems theory or cybernetics (Wiener, 1948). Cybernetics works on the principle of negative feedback which brings a system back into equilibrium, usually to a set of predetermined standards; anyone who has used the log frame approach in development will recognise it as a cybernetic system with the predetermined standards as the milestones. Latterly, systems thinking has developed into systems dynamics and beyond, to include theories of emergence and complexity, such as complex adaptive systems theory (Kauffman, 1995; Holland, 1998; Jackson, 2000). Systems dynamics includes the idea of both positive and negative feedback, and has been popularised by writers such as Argyris (1982), Senge (1990) and Schön (1991).

What systems theories have in common is the concept of an organisation as a whole with a boundary. The whole can be disaggregated into parts, or in organisational terms, levels, where higher levels, in the shape of senior managers can act upon the lower levels to bring about change to the whole system. Equally, realigning the parts can influence the whole: many INGO strategies also portray societies as wholes, or systems, which can then be redesigned. The Department for International Development (DfID) recently developed its 'drivers of change' method by which it intended to 'seek(s) to identify the political institutions, structures and agents that can act as key levers to enable pro-poor change and therefore improve the effectiveness of aid' ${ }^{2}$ The direct linkage between cause and effect, identifying 'levers' which can be pulled to bring about predictable change, are explicit here. This kind of thinking is also manifest in many INGO strategies, where interventions are planned at the district, regional and national or even continental 'levels' in order to bring about realignment of the parts and the whole. Management theories and strategies based in systems thinking imagine that change can be predictable in advance, and privilege the idea of wholesale transformation through the agency of leaders and managers 'designing' solutions to problems. In this sense they are methodologically individualistic in

${ }^{2}$ http://www.gsdrc.org/go/topic-guides/drivers-of-change 
that the INGO and its staff are placed at the centre of activities as principal agent, with all the activities of other agents relegated to the assumptions and risk factor columns of the proverbial log frame. This methodological individualism leads in turn to an individualised understanding of leadership: the exceptional leader is one who can foresee and suggest possibilities for redesigning parts and whole by being 'visionary'.

We commented above on the particular manifestation of management theory in INGOs where managers make use of a systemic understanding of change charged by utopian idealism. In a paper commenting on the way that the understanding of management in INGOs has changed owing to globalisation, Dichter (1999) argues that INGOs have now become more corporation than church. In this paper we contend that they still carry characteristics of both corporation and church since many managers in INGOs make direct appeals to the collective moral purpose of their organisations when they develop strategy. It is in this area in particular that it seems to us that the idea of professional and moral 'mission' come together (Mowles, 2008). Many organisations have adopted a variation of Ackoff's (2006) idealised design method to make strategy, which is again based in systemic understandings of how change comes about. Rather than just depending upon machine analogies, idealised design gives pride of place to people and their perceptions, values and beliefs:

The aim of idealised design is to enthuse the participants with a vision of what their organisations might be like and to endow them with a mission to create the future on this basis. The process is meant to generate consensus, mobilise the stakeholders with a crusading zeal, and reveal that only the participants' limited imaginations prevent them getting the future they most desire, right here, right now (Jackson, 2000, p. 244).

Prominence is given to the role of the imagination in envisioning an end state which staff can work towards. The idea behind Ackoff's thinking is that, whatever conflicts may exist initially, the enthusiasm for the mission and the participatory planning approach will enable staff to be united together in the enterprise. The process of enthusing staff and managers, and getting them excited and motivated is in acknowledgement of the differing world views that may exist in any organisation which can be overcome by a collective undertaking to do good.

To sum up the argument of this section so far: systems theories privilege the idea of alignment, often realignment, of the parts and the imagined whole. They have proved very powerful in the fields of biological and engineering sciences where the systematic disaggregation of objects has genuinely led to the advancement of our understanding of phenomena in the natural world. When applied to processes of social interaction like human development, however, systems theories have severe shortcomings. When adopting them in taken for granted management practice, managers in INGOs can come to understand unanticipated contextual and contingent circumstances unforeseen in the more abstract and decontextualised planning processes to be so much 'noise' which needs to be managed away. They privilege instead idealised and pre-reflected targets of these often highly utopian projects of social transformation over and above the daily experience of trying to implement them with others. Staff are rewarded by managers on the basis of being able to 'deliver' these projects, since they are bound both by the public promises of transformation they have made, and often, in addition, by the contractual obligations they have entered into with major donors. The relationship with local NGOs, usually termed the INGO's partners, in turn become conditioned by the drive to 'deliver' on the project targets, and partners are often 
offered 'capacity building', or training, in order to encourage them to conform more closely to ways of working and organising which are recognised by INGOs and major Northern donors. We have become aware of the pressure that staff from local NGOs come under as we undertake consultancies in the South, because they consistently complain to us about their unrealistic work targets which take insufficient account of their local turbulent context, and to which they may not have directly contributed. The focus on pre-reflected 'results', rather than paying attention to both expected and unexpected consequences of intervention in communities, can place the notion of partnership under severe strain.

What concerns us is the potential for oppression in these ways of thinking and acting, both of staff in INGOs and the partner organisations in developing countries. They can lead staff in INGOs into working in ways which they would claim to be the very opposite of the values of participation, engagement and partnership which they would aspire to uphold. Sometimes our consultancies with INGOs turn on our ability to improve damaged relationships between INGOs and their partners. We understand social development to be an essentially contested, political and messy process, which will inevitably result in conflict and both expected and unexpected results. By privileging the abstract and the idealised, we believe that the dominant paradigm for understanding the management of development attempts to cover over the inherently conflictual nature of negotiating with others about how to go on together. Managers who take up these taken for granted ways of working assume social change and innovation to be both predictable in advance and achievable by linear and logical planning methods. By doing so they are acting ideologically in the sense that the moral philosopher Alasdair McIntyre described it in an essay discussing scientific methodology:

It is a central feature of established social orders that they tend to embody in their social institutions denials of the centrality of conflict, argument, contestability and unpredictability in human life; and it is a central feature of most social theories that they share this characteristic with most social orders...social victory at this deep level is the achievement of inducing those who participate in the practice to agree in conceptualising their activities in such a way that one of the contestable interpretations no longer appears contestable, but simply how things are- 'the facts' (1998, pp. 58-59).

What concerns us is that this way of working is in effect, and in McIntyre's terms, a new form of domination of the developing world. Although the domain of international development has become more highly professionalised and more complex to the extent that the larger INGOs now employ thousands of staff in tens of countries, ways of thinking and acting have not kept pace with this complexification. Managers in the sector are using methods adopted uncritically from the private sector which are also being challenged there. There is still a lot of scope for radical rethinking what managers in INGOs understand and practice, and it is this that we will start to explore below.

\section{INSIGHTS FROM THE COMPLEXITY SCIENCES}

In the development sector, a number of commentators (Roche, 1994; Mosse, 1998; Davies, 2004, 2005; Hamdi, 2004; Eyben, 2006; Simpson and Gill, 2007) have argued for a more 
complex understanding of how change comes about and the role of INGOs in this process, often drawing on the complexity sciences, for example, complex adaptive systems theory (Gell-Mann, 1994; Holland, 1998). Whilst appreciative of the unexpected, and more tolerant of ambiguity, paradox and power, what is common to all of these authors is the tendency to understand insights from the complexity sciences as being something which can be harnessed or accommodated within existing systemic ways of understanding development management. They can argue for an appreciation of insights from theories of complexity in instrumentalised ways, like Pasteur (2006, p. 22) for developing new 'tools for dialogue and holistic analysis', or like Simpson and Gill (2007, p. 220) for 'a complete design methodology' even one 'that moves away from the objectivist basis of existing design systems'. Others, in drawing on complex adaptive systems theory, have argued, after Wheatley (1994) and Pascale et al. (2000), that one central insight drawn from the complexity sciences means that staff in organisations should operate by 'simple rules', and by doing so managers and consultants are capable of 'unleashing' the power of complexity applying it to ensure better results and more creativity. This understanding seems to be derived from the idea that organisations are like natural living systems, which, according to Wheatley and Pascale, emerge and grow in their environment according to simple rules of nature - if one could identify and use these simple rules then the process of organisational development would be easier. Griffin (2002) has offered an extensive critique of this position and the way in which complex and paradoxical phenomena are drawn into a systemic understanding of organising which in the end reduces the complexity of the concept under discussion.

A number of other organisational theorists problematise the instrumental application of complexity theory to organisations (Chia, 1998; Tsoukas and Hatch, 2001; Tsoukas, 2006). They reject the direct transfer of models and theories from the natural sciences and explore how, if at all, complexity science ideas may be located in the context of established social theory relevant to organisations. They therefore depart from the problem-solving, performance-improving mentality of the authors referred to in the previous paragraph. They move away from the implicit search for a manageable relation between emergent properties and process of interaction towards an engagement with the somewhat messy and often unintelligible and unpredictable nature of everyday life in organisations. This approach leads Chia to reject complexity thinking as an extension of reductionism which is inadequate for understanding organisations, while Tsoukas and Hatch highlight a subjective counterpart taking the form of 'narrative' complexity.

Another group of authors (Stacey et al., 2000; Stacey, 2007) deny a separation between subjective and objective experience of human action and draw attention to the inherently paradoxical and transformative nature of everyday experience. They claim to present a more radical understanding of complexity theories in relation to human action, a theory of complex responsive processes, which privileges communicative interaction, power relating and the spontaneous and improvisational nature of collective human action. They do so in an interpretation of one of the central insights from complexity theories, namely, that global patterns emerge only as a consequence of the interactions of local agents. These global patterns both constrain what it is possible for local agents to do, and enable them at the same time, and in this sense they are a paradoxical phenomenon; local agents form, and are formed by the global pattern both at the same time. However, it is important to understand that no one is in overall control of what is happening, and although patterns of relating tend in a particular direction, the exact global pattern that emerges is 
unpredictable. Everything that local agents do, then, including nothing, will have an effect on the patterning that emerges over time.

In this paper, we will take up this radical manifestation of complexity theory, to make a claim for a different approach to management and practice in INGOs. We will do so in the belief that it offers an understanding and methods more appropriate for coming to terms with the complexity of situations that face managers and staff in the day-to-day practice of their work in international development. Stacey et al. developed their theory drawing on theorists who have themselves written extensively about the paradoxical nature of interdependent people trying to achieve things together. By focussing on power relating, taking up the social theories of Elias (1939/1991, 1939/2000), the theory of language and mind drawing on Mead (1934) it encourages a recursive reflexivity of method (Bourdieu and Wacquant, 1992; Giddens, 1993) which takes into account both subject and object of study, and understands them to be in paradoxical relation. The method associated with complex responsive processes of relating tends less towards problem solution and more towards a shared restatement of organisational problems as staff members co-create their organisational futures together. In this way, they more closely approximate to some of the central insights of self-organisation and emergence without instrumentalising them, or being impelled to simplify them.

\section{THE RADICAL IMPLICATIONS OF THE PATTERNING OF INTERACTIONS-NORBERT ELIAS}

In the paragraphs above we argued that the dominant way of understanding change is to valorise and centralise the role of the staff in the particular INGO, and to assume that social transformation is an end point reached in logical, causal and predictable steps. Planning tools such as the logical framework are mostly unconcerned with the process of achieving what is set out in the plan. When big donors such as DfID make large sums of money available, like they have done recently through the Governance and Transparency Fund, INGOs are invited to submit proposals with plans that predict up to 5 years in advance how INGOs and their partners will be working together, what impact this will have and what money they will need to do so. Proposals are judged on their logical coherence as well as their fit with DfID's criteria, and are obliged to come up with criteria of success which are specific and measurable.

Funding proposals judged by the sociologist Norbert Elias would have been evaluated according to very different criteria. In his seminal work The Civilising Process (1939/ 2000), Elias sets out a neo-Darwinist thesis on the origins and development of societies. He was much exercised by what he regarded as a tendency in Western thought to deprioritise and ignore process and reduce it to fixed and unvarying concepts. This is a phenomenon that is understandably reflected in language, with scientific vocabulary in particular, according to Elias, having a tendency to reify and abstract phenomena in a way that makes them fixed and static. Elias used the word 'figuration' as a shorthand to mean networks of interdependent people engaged in asymmetrical power relations, since it implied for him a much more dynamic way of conveying the shifting nature of human relations. Goudsblom (1977) sums up the key insights of Elias' sociology as follows:

1. Human beings are interdependent in a variety of ways and their lives are significantly shaped by the figurations that they form together. 
2. These figurations are constantly subjected to change, some ephemeral and swift, others slower but perhaps more long lasting.

3. Long-term developments in changes to human figurations have been and continue to be unplanned and unforeseen.

4. Human knowledge arises within these human figurations and is an important aspect of their overall development.

One of the central insights of Elias' sociology is the idea that most significant change is unplanned and unforeseen, and is the result of a web of interdependent actions informed by past actions. It is very difficult to reconcile with the notion that there are 'levers of change' that staff in an INGO might identify and 'pull', or that we can decide on the change that we want to bring about and work backwards from there.

Arguing against the idea that change comes about through intentionality of individual actors or groups of actors alone, the Civilising Process demonstrates how we are bound together in complex webs of interdependency, an essential characteristic of which are unstable relationships of power. Given the large number of people involved in complicated social processes such as international development, and the degree of complexity that arises as a consequence of their many and conflicting intentions, it comes as no surprise that our actions will bring about things we intend as well as things we would like to prevent.

As the moves of interdependent players intertwine, no single player nor any group of players acting alone can determine the course of the game no matter how powerful they may be. . . It involves a partly self-regulating change in a partly self-organising and self-reproducing figuration of interdependent people, whole processes tending in a certain direction (1991, p. 146/147).

Elias' idea of continuous but interrelated changes comes very close to the concept of the emergent properties of agent-based computer modelling which leads to the theory of complex adaptive systems theory outlined above. We are shaped by the dynamic process of change in which we are engaged with others, and in the whole history of changes that have led to this point. However, our knowledge and understanding of the figurations in which we are caught is always imperfect and often inaccurate. When we base strategies on our imperfect knowledge of the situation in which we are caught up there will always be unintended consequences that we cannot foresee. The turbulence that we experience as we act on our intentions will give us a much clearer indication of how imperfect our knowledge was to start with. We should expect not to achieve what we set out to achieve in the way that we originally intended.

\subsection{The Idea of the Game-Elias and Bourdieu}

To illustrate this, Elias drew on game models to demonstrate that interactions between humans are contests, where power is a quality of the relationship between them dictating who can prevail over the other. In situations where one player is stronger than the other in a two-player game like tennis, the contest can be resolved easily and quickly, with the stronger player dictating the shape and often the speed of victory. In a match which is more 
evenly balanced, the two players are obliged to adapt their strategies mutually as the game unfolds, since neither is able to dictate to the other:

Both players will have correspondingly less chance to control the changing figuration of the game; and the less dependent will be the changing figuration of the game on the aims and plans for the course of the game which each player has formed by himself. The stronger, conversely, becomes the dependence of each of the two players' overall plans and of each of their moves on the changing figuration of the game on the game process. The more the game comes to resemble a social process, the less it comes to resemble the implementation of an individual plan. In other words, to the extent that the inequality in the strengths of the two players diminishes, there will result from the interweaving of moves of two individual people a game process which neither of them has planned' (Emphasis Elias, 1978, p. 82).

Elias goes on to extrapolate from this to a multi-player game on many levels, which would be a set of circumstances more akin to the situation that staff in INGOs find themselves in:

But as the number of players grows the individual player not only finds the game increasingly opaque and uncontrollable, but he also gradually becomes aware of his inability to understand and control (Ibid: 85).

There are a number of possibilities of what can happen when the game becomes too complex, including players separating out into two tiers, where exactly the same power dynamics begin to play themselves out within the tiers as well as between them. The effect of the moves of large numbers of players has an effect on the possibilities for movement of every single player. The generalised tendencies of the large number of people acting together operates separately from the individual intentions of individual players or groups of players. It is not a separate phenomenon but can be considered separately. For Elias, the relationship between the individual and society was not a mysterious one: there was no individual without society and vice versa. Society is the plural of the individual.

Bourdieu (1990), the anthropologist turned sociologist, also alludes to the game as a metaphor for the way that we come together to act. For Bourdieu we do not just learn the game but are born into it and take part in it first of all as an unconscious act. The shape and structure of the game is informed by a 'long, slow process of autonomisation' shaped by the habitus which Bourdieu defines as a set of enduring dispositions formed by historical and social context. We are products of our cultural and class history just as we are contributing to the creation of that history at the same time. Because the two are inextricably linked, it is impossible to say that one is logically derived from the other, to imply that having $\mathrm{X}$ intention will result in $\mathrm{Y}$, because this would imply cutting the action out of its iterative and circular temporality. By analysing the rituals of the Kabyle people in Algeria, Bourdieu concluded that practical judgement occurs with improvisation on and around the habitus:

...only a virtuoso with perfect command of his 'art of living' can play on all the resources inherent in the ambiguities and uncertainties of behaviour and situation in order to produce the actions appropriate to each case, to do that of which people 
will say 'There was nothing else to be done', and do it the right way...the 'art' of the necessary improvisation which defines excellence (Bourdieu, 1977, p. 8).

Bourdieu also sets out a theory of emergence, a theory of unplanned emergent novelty grounded in paradox, which is located in a very different concept of time, which he counterposes with a scientific understanding of time:

Science has a time which is not that of practice...scientific practice is so 'detemporalised' that it tends to exclude even the idea of what it excludes: because science is possible only in relation to time which is opposed to that of practice, it tends to ignore time and, in doing so, to reify practices (Ibid: 9).

Bourdieu's idea of the time of practice is very close to the concept of time first articulated by Augustine's [354-430] (1998) 'present of the past, present of the present and present of the future' (Book X, Memory and Book XI, Time and Eternity) where it is difficult to disentangle the meaning of an act cut out from the complex background of history and a future which the act provokes. ${ }^{3}$ Science, however, describes an act as a phenomenon singled out from this background. For Bourdieu, improvisation, which is a response in the present drawing on the past and anticipating the future, is never something one can get on top of and master. It becomes aware of itself only through reflexivity, after the event:

The idea of a practical logic, a 'logic in itself', without the conscious reflexion of logical control, is a contradiction in terms, which defies logical logic. This paradoxical logic is that of all practice, or rather of practical sense. Caught up in 'the matter in hand', totally present in the present and in the practical functions that it finds there in the form of objective potentialities they contain; it can only discover them by enacting them, unfolding them in time (Bourdieu, 1990, p. 92).

Rather than being reliant on investing so much on working out what we intend to do before we act, Bourdieu is observing instead that we can only really make sense of our actions after we have acted and observed the consequences. Like Elias, he argues against the ahistorical and abstract tendencies of natural science methods applied to human interaction, since they over-emphasize causality and linearity, implying that human action is more rational and pre-reflected than it actually is.

\subsection{What Reproduces Existing Theory and Practice?}

We suggested earlier that we would offer some reasons why it is that there is such defensiveness around ways of working and understanding management theory and practice in international development and we will do so drawing on Elias and Bourdieu.

In an increasingly professionalised sector, development professionals and managers are caught up in Elias' terms in a power relationship with each other. We depend on others and they depend on us, and this dependency may take many forms:

\footnotetext{
${ }^{3}$ This concept of time is significantly reformulated in the work of Hegel (1807/2004), Husserl (1926/1966) and Mead (1934), among others.
} 
...we have become dependent on them by their use of naked force or by our need to be loved, our need for money, healing, status, a career or simply for excitement (Elias, 1998, p. 132).

It is very hard to gainsay management practices that one has come to doubt if one also aspires to a career within the sector. Bourdieu too warns against the consequences of calling the game into question. International development constitutes what Bourdieu called 'a field of specialised production' (1991, p. 58) where the players have both a belief and an investment in keeping the game going. They constantly struggle with each other to establish the game and its legitimacy, and this very struggle tends itself to reproduce the game and the commitment of the players, and those who would like to join it. The game is sustained by a kind of collusion amongst the players. As Bourdieu says, the game is only over when the players ask whether it is worth the candle.

\section{SUMMARY OF THE ARGUMENT SO FAR}

We have counterposed existing concepts of management and change which dominate the INGO sector with a set of alternative theories derived from ideas of self-organisation and emergence, drawing on two theorists in particular who have written into this way of understanding. Rather than portraying social interaction as rational, linear and predictable, our alternatives describe a web of human interactions which are predicated on the power relationships and interdependencies of the actors. Because of the scale and complexity of the game being played by these actors, it can only result in unpredictable and unexplained consequences no matter how clear and logical the strategy pursued by any actor. This is a paradoxical world where we are forming and being formed by the web of interactions both at the same time. Our knowledge of the game we are playing is imperfect, and we only realise this as we play the game and reflect on the consequences of having played it. Rather than displaying an 'if...then' causality, our understanding of the temporality of what we are involved in is cyclical: we act in the present, informed by the past and in anticipation of the future, and our understanding of that past is constantly revised as a result of our acting.

Since we chose a title for this paper which promised a focus on the practical consequences of taking up insights from the complexity sciences for management practice in INGOs, it behoves us to go on to explore some of these. We have already drawn attention to the sensitivity that surrounds even a gentle critique of existing practice, and have pointed to some of the reasons that might inform this sensitivity. It has sometimes been suggested that we are somehow against planning or against motivating staff to fulfil the organisation's mission. We oppose neither. In contrast, what concerns us most, however, is the lack of reflexivity that informs a lot of management practice in INGOs which we believe is in danger of becoming another form of domination, especially as it is reproduced through INGOs' own capacity building programmes with their Southern partners. INGOs are in danger of intervening into other peoples' societies driven by their own demands all the while co-opting and coercing their partners into the process.

We are concerned too about the lack of humility in the scale of claims being made for social development work of any kind, which can only come back to haunt those making them. It is no more possible to put a full stop to child abuse than it is to rewrite the future for children, as recent NGO campaigns would claim. We are not naïve in understanding that 
being more humble and provisional in making claims for the work that they may affect the ability of managers in INGOs to raise funds for what they intend.

\section{DISCUSSION AND CONCLUSIONS: THE CONSEQUENCES FOR WORKING TOGETHER}

What would it mean to manage and to practice in organisations committed to a more complex, paradoxical and contingent understanding of the world? What would happen if we turned our attention from the grand and the abstract towards the day-to-day difficulties of trying to achieve things together, which is what it would mean to understand the process of organising as complex processes of relating?

\subsection{Planning, Action and Reflection}

In formulating plans to orient staff and to gain funding from donors for what they are doing, managers in INGOs are obliged to act with intention and spell out what these intentions are. However, no amount of logic could possibly yield the amount of detail that one is obliged to provide to donors about activities that will take place up to 5 years in advance. And if we accept theories of emergence as the basis for understanding how social phenomena arise, we can expect our plans to achieve some of the things we intend, but a lot of things which are unexpected and perhaps unwanted. What happens as consequence of our forming plans and acting on them must become, then, the primary focus of our attention. We would aim for, in Bourdieu's words: 'a highly unlikely combination of definite ambition, which leads one to take a broad view, and the great modesty indispensable in burying oneself in the fullest detail of the object' (1992, p. 252), if we take the object to be what happens as a consequence of our actions and our experience of it. This would suggest action, and continuous reflection on action to be at the heart of what it means to make sense of one's interventions with others. Elias (1987) formulates this paradox as simultaneous involvement and detachment. We see this as a basis of understanding the intensely political nature of social interaction.

We put this forward as a very different understanding of what it means to act with intention and to commit to promises of transformation that are endemic in the INGO sector. What this suggests is a process of emergent planning where the plan itself and the assumptions behind it are subject to the same kind of reflexive examination as the work. The expected and unexpected consequences of working would both be valid data for consideration and review, rather than the latter being considered an aberration and a deviation from the plan. Planning could come to be a continuous process of recognition and reflection on action and the consequences of action that came to value the process of becoming as much as the outcome itself. Managers and staff would understand planning as a process of developing a deeper understanding of the game which is being played and the political constraints and opportunities that this game offers.

\subsection{Management Practice}

At its most basic, performance management in INGOs has come to mean much the same as it does elsewhere: employees are evaluated against targets that have been set at the 
beginning of the year and are appraised and rewarded accordingly. In our experience, depending on the manager concerned, we are led to believe by people we interview in organisations that these are not always the most enlivening of encounters. Targets set at the beginning of the year will often seem remote and divorced from the day-to-day experience of trying to realise them. We would suggest, drawing in particular on Elias and Bourdieu, that we could come to understand performance as it is understood in an artistic context, such as improvisational theatre or music, particularly jazz. Employees could be rewarded for their ability to interpret and respond to the circumstances that they meet in their day-today work with others, their ability to improvise. Excellence, according to Bourdieu, is 'the art of necessary improvisation' $(1977$, p. 8): by this he means improvising around a set of objective constraints, or habitus, which could comprise the social conditions of the country where the work is taking place as well as the policies and procedures of the INGO concerned. That is to say, the employee is not rewarded for making things up as they go along, but being creative and adaptive in the game they are obliged to play. We could come to understand 'accountability' as the process of accounting for why one acted the way one did within an overall account of the game that is playing out in their particular environment and circumstances.

This could become a joint enquiry undertaken by both the manager and the managed where the primary data are the practitioner's own day-to-day experience of trying to do the work, but where the aim is to make subjective experience more objective through reflection and discussion with the manager and others. The process aims to reveal the interpretive assumptions that are often implicit in our work with others in the company of what the early pragmatic philosopher Peirce (1998) originally termed 'a community of inquirers'. In doing so the practitioner and manager could open themselves up to different ways of working and perhaps move themselves on from stuck and less productive ways of working with peers.

If we consider development as a process, rather than as an end state arbitrarily determined by the constraints of having to write project plans and funding proposals, then management becomes not just a reductive exercise in trying to achieve predetermined targets, but also a broader experiment in research, exploration, and a broader understanding of accountability (giving an account of), which we began to set out above. Managers and staff could be encouraged to take their daily practice seriously, and be further encouraged to consider themselves to be active researchers more broadly in the life of the messy and intensely political organisations and societies in which they are struggling to make a difference.

\subsection{Ethical Engagement With Others-Rediscovery of the Political}

In presenting a critique of common management theories and planning methods we offered the observation that they were methodologically individualistic. By this we mean that they can sometimes ascribe quasi-heroic powers to the agency of the staff in the INGO to bring about the desired social change. They promise transformation in way that can cast their partners and local beneficiaries as bit part players in their own destinies. We suggested that contemporary taken for granted ways of managing are ideological in the sense that they dominate partner organisations in the South at the same time as pretending not to do so. When INGOs take it upon themselves to 'capacity build' others, there is a danger of implying that they have everything to teach and nothing to learn. What concerns us is a 
practice of social development which is insufficiently social: we are suggesting, rather, a greater appreciation of the interdependencies between us and the people we purport to be helping, and the power relationships we co-create together. This implies a greater exploration of what we take for granted.

If we consider the practice of management and development in more social, experiential and exploratory terms we would also take our experience of working with others as being relevant data for knowing how to proceed. Staff in INGOs can sometimes interpret resistance by staff in local NGOs to their offers of training and support as evasiveness or lack of openness (transparency) to what they consider to be 'best practice'. However, in our view, in coming to understand what we intend by what we do, we would need to take into account the intentions of those towards whom we have intentions. This is a struggle for mutual recognition rooted in negotiation which allows for a more radical openness to others. It can be, as the contemporary moral philosopher Charles Taylor says, a painful, if instructive process:

The analogous point here is that in coming to see the other correctly, we inescapably alter our understanding of ourselves. Taking in the other will involve an identity shift in us. That is why it is so often resisted and rejected. We have a deep identity investment in the distorted images we cherish of others (2002, p. 295).

The practical consequences of paying attention to the day-to-day interactions with others involve exploring the language and concepts that we use in doing so. We are drawing attention to the radical possibilities of responding to emergent phenomena which could genuinely transform our relationship with others and the work that we do together. This involves our acknowledging both intended and unintended consequences of acting together to bring about change and negotiating what we think it might mean. We offer this as one way or reintroducing the political into international development. Rather than depending upon ways of working which are tantamount to a form of domination of others, we are arguing instead for radical engagement with the other which would involve being open to the difference that this could bring. Instead of predicating our intentions on the idealised transformation of others, we could pay attention instead to the daily, difficult and messy experience of working with others to achieve things together, and the opportunities for changing ourselves that these present.

\section{REFERENCES}

Ackoff R. 2006. Idealized Design: How to Dissolve Tomorrow's Crisis...Today. Wharton School Publishing: New York.

Argyris C. 1982. Reasoning, Learning and Action: Individual and Organisational. Jossey Bass: San Francisco.

Augustine. [354-430], 1998. Confessions (trans. Chadwick, H.). Oxford World Classics: Oxford. Bourdieu P. 1977. Outline of a Theory of Practice. Cambridge University Press: Cambridge.

Bourdieu P. 1990. The Logic of Practice. Polity: Cambridge.

Bourdieu P. 1991. Language and Symbolic Power. Polity: Cambridge.

Bourdieu P, Wacquant L. 1992. An Invitation to Reflexive Sociology. University of Chicago Press: Chicago. 
Chia R. 1998. From complexity science to complex thinking: organization as simple location. Organization 5(3): 341-370.

Cooke B. 2004. The managing of the (third) world. Organization 11(5): 603-629. ISSN 1350-5084.

Dar S, Cooke B (eds). 2008. The New Development Management: Critiquing the Dual Modernization. Zed Books: London.

Davies R. 2004. Scale, complexity and the representation of theories of change. Evaluation 10(1): 101-121.

Davies R. 2005. Scale, complexity and the representation of theories of change Part II. Evaluation 11(2): 133-149.

Dichter T. 1999. Globalisation and its effects on NGOs: effloresence or a blurring of roles and Relevance? Nonprofit and Voluntary Sector Quarterly 28(4): 38-86.

Elias N. 1939/1991. The Society of Individuals. Blackwell: Oxford.

Elias N. 1939/2000. The Civilising Process. Blackwell: Oxford.

Elias N. 1978. What is Sociology? Hutchinson: London.

Elias N. 1987. Involvement and Detachment. Blackwell: Oxford.

Elias N. 1998. Norbert Elias on Civilisation, Power and Knowledge: Selected Writings. University of Chicago Press: Chicago, IL.

Eyben R. 2005. Donors' learning difficulties. Increased aid: minimising problems, maximising gains. IDS Bulletin 36: 98-107.

Eyben R (ed.). 2006. Relationships for Aid. Earthscan: London.

Gell-Mann M. 1994. The Quark and the Jaguar. Freeman: New York.

Giddens A. 1993. New Rules of Sociological Method. Stanford University Press: Stanford.

Goudsblom J. 1977. Sociology in the Balance. Blackwell: Oxford.

Griffin D. 2002. The Emergence of Leadership: Linking Self-Organisation and Ethics. Routledge: London.

Hamdi N. 2004. Small Change: About the Art of Practice and the Limits of Planning in Cities. Earthscan: London.

Hegel GWF. 1807/2004. The Phenomenology of Mind. Dover Classics: London.

Holland J. 1998. Emergence from Chaos to Order. Oxford University Press: New York.

Husserl E. 1926/1966. Analysen zur passive Synthesis. Martinus Nijhoff: Den Haag.

Jackson M. 2000. Systems Approaches to Management. Kluwer Academic: New York.

Kauffman S. 1995. At Home in the Universe. Oxford University Press: Oxford.

Lewis D. 2001. The Management of Non-Governmental Development Organisations. Routledge: London.

McIntyre A. 1998. The McIntyre Reader, Knight K (ed.). Polity: Cambridge.

Mead GH. 1934. Mind, Self and Society From the Standpoint of a Social Behaviourist. University of Chicago Press: Chicago.

Mosse D (ed.). 1998. Development as Process: Concepts and Methods for Working With Complexity. Routledge: London.

Mosse D. 2005. Cultivating Development: An Ethnography of Aid Policy and Practice. Pluto: London.

Mosse D, Lewis D (eds). 2005. The Aid Effect: Giving and Governing in International Development. Pluto: London.

Mowles C. 2007. Promises of transformation: just how different are development INGOs'. Journal of International Development 19(3): 401-411

Mowles, C. 2008. Values in international development organisations: negotiating non-negotiables. Development in Practice 18(1): 5-16. 
Murphy J. 2005. The World Bank, INGOs, and civil society: converging agendas? The case of universal basic education in Niger. Voluntas: International Journal of Voluntary and Nonprofit Organizations 16(4): 353-374.

Pascale R, Milleman M, Gioja L. 2000. Surfing the Edge of Chaos: The Laws of Nature and the New Laws of Business. Three Rivers Press: New York, New York.

Pasteur K. 2006. Learning for development. In Relationships for Aid, Eyben R (ed.). Earthscan: London, pp. 94-112.

Peirce CS. 1998. Pragmatism as a Principle and Method of Right Thinking: the 1903 Harvard Lectures on Pragmatism by Charles Sanders Peirce, Turrisi PA (ed.). State University of New York Press: Albany, New York.

Quarles van Ufford P, Giri KG (eds). 2003. A Moral Critique of Development: In Search of Global Responsibilities. Routledge: London.

Roche C. 1994. Operationality in turbulence: the need for change. Development in Practice 4(3): $160-172$.

Schön D. 1991. The Reflective Practitioner-How Professionals Think in Action. Avebury: Aldershot.

Senge P. 1990. The Fifth Discipline: The Art and Practice of the Learning Organisation. Doubleday: New York.

Simpson R, Gill R. 2007. Design for development: a review of emerging methodologies. Development in Practice 17(2): 220-230.

Stacey R. 2007. Strategic Management and Organisational Dynamics: The Challenge of Complexity. Prentice Hall: London.

Stacey R, Griffin D, Shaw P. 2000. Complexity and Management: Fad or Radical Challenge to Systems Thinking. Routledge: London.

Taylor C. 2002. Understanding the other: a Gadamerian view on conceptual schemes. In Gadamer's Century: Essays in Honour of Hans-Georg Gadamer, Malpas J, Arnswald U, Kertscher J (eds). MIT Press: Cambridge, MA.

Tsoukas H. 2006. Complex Knowledge: Studies in Organizational Epistemology. Oxford University Press: Oxford.

Tsoukas H, Hatch MJ. 2001. Complex thinking, complex practice: the case for a narrative approach to organizational complexity. Human Relations 54(8): 879-1013.

Wallace T, Crowther S, Shepherd A. 1997. Standardising Development: Influences on UK NGOs' Policies and Procedures. World View Publishing: Oxford.

Wallace T, Bornstein L, Chapman J. 2006. The Aid Chain: Commitment and Coercion in Development NGOs. IT Publishing: London.

Wheatley M. 1994. Leadership and the New Science: Learning About Organization From an Orderly Universe. Berret Koehler: San Francisco.

Wiener N. 1948. Cybernetics: Or Control and Communication in the Animal and the Machine. MIT Press: Cambridge, MA. 